\title{
LAS MINAS DE ORO DEL RÍO SANTA BÁRBARA EN EL AUSTRO ECUATORIANO: DE LAS QUEJAS ESPAÑOLAS COLONIALES DEL SIGLO XVII A LA IDEOLOGÍA PREHISPÁNICA PROFUNDA DE LOS PUEBLOS ABORÍGENES*
}

\author{
ECUADOR SOUTHERN REGION SANTA BARBARA GOLD MINES: \\ OF THE XVII CENTURY SPANISCH COLONIAL COMPLAINS TO THE DEEP \\ IDEOLOGY OF THE PREHISPANIC ABORIGINAL PEOPLE
}

\author{
Alden Yépez**
}

\begin{abstract}
Algunas empresas españolas de la Colonia temprana se interesaron en buscar oro, plata y azogue en la región del austro ecuatoriano. Varias investigaciones enfatizan el constante problema que tuvieron los mineros españoles en sus actividades, debido a la escasez de mano de obra indígena, la deserción de ellos o las enfermedades que los azotaron. Pocos estudios han centrado la atención en las creencias indígenas impregnadas en las crónicas de los españoles, cuando estos relatan cómo ellos se resistían a la extracción de los metales. En este manuscrito se revela cómo a partir de la extracción del oro en las minas de Santa Bárbara podemos conocer las creencias animistas de los indígenas de esa época y nos permiten analizar su conexión con una religiosidad mucho más profunda, herencia religiosa andina de la época prehispánica.
\end{abstract}

Palabras claves: Minería colonial, río Santa Bárbara, creencias animistas, ideología prehispánica.

Some Spanish early colonial enterprises were interested in gold, silver and quicksilver searching in Ecuador's South Region. Many investigations outline the constant problem faced by the Spanish miners in their activities, due to the lack of indigenous hand labor, their work defection or the sickness faced by them. Just a few studies have focus its attention on the indigenous believes written on the Spanish chronicles, when they describe how the indigenous resist to the minerals extraction activities. This manuscript reveales how from the Santa Barbara gold mines we can acknowledge the animistic believes of that era and how they allowed us to analyze their connection to a profound inherenced andean religiosity of the prehispanic times.

Key words: Colonial mining, Santa Bárbara river, animistic believs, prehispanic religion.

\section{Introducción}

Las creencias animistas de los "indios mitayos" que trabajaron para mineros españoles durante el siglo XVII han sido poco estudiadas por los etnohistoriadores, porque las relaciones socioeconómicas que contextualizan las labores extractivistas de la época son más abundantes en las crónicas. Las investigaciones históricas acerca de la minería en la región austral del Ecuador no escapan a esta premisa. Sin embargo la importancia del contexto socioeconómico en el que se inscribe este trabajo tampoco pudo pasar inadvertido por nosotros, porque nos permitió entender por ejemplo por qué en una época de decadencia de la minería en Ecuador se barajaron ideas tan peculiares como las de Francisco Fuentes de Ávila, quien en 1638 pretendía extraer oro no de socavones o del lecho de los ríos, sino del fondo de los lagos, mediante su vaciado, rompiendo los riscos de las montañas. Durante este procedimiento encuentra con sorpresa que los indígenas temen la represalia de las montañas y lagunas, y que llevaban a sus casas fragmentos de las rocas como amuletos protectores. Estos elementos dejan abrir un rico debate acerca de las creencias religiosas animistas de los indígenas de esta época y de su conexión con una ideología religiosa mucho más profunda, anclada en el pasado prehispánico del Mundo Andino Antiguo.

\section{Breve ordenamiento cronológico retrospectivo de la explotación minera en el austro ecuatoriano (siglo XVI-siglo XXI)}

El austro ecuatoriano ha sido considerado como una región minera comparable en riqueza mineral

\footnotetext{
* Resultado del apoyo económico recibido de la Pontificia Universidad Católica en Quito con oficio N R.519.

** Pontificia Universidad Católica del Ecuador, Escuela de Antropología, Quito. Ecuador. Correo electrónico: amyepez@ puce.edu.ec
} 
con otras regiones de América del Sur como Bolivia por el estaño, Chile por el cobre y Perú por el oro. Forma parte entonces del sistema minero occidental de América del Sur. Los principales minerales que se han explotado históricamente allí han sido el oro, la plata y en menor medida el azogue (Chacón 1986). La tónica general histórica de la explotación minera ecuatoriana ha sido la extracción de los concentrados metálicos para su fundición y refinación en el exterior. Sin embargo la extracción no ha sido continua y se ha visto afectada por largas interrupciones, en tanto que su activación se explicaría por intereses desarrollistas que buscaron (y buscan) activar la economía del país de manera esporádica.

En abril de 2008 se expidió en Ecuador el Mandato Minero para tratar de poner orden un manejo caótico de las reservas más grandes que tiene el país por medio de la creación de una empresa minera industrial del Estado (ENAMI: Empresa Nacional Minera) con socios extranjeros con experiencia en la explotación de metales (Sacher y Acosta 2012: 18-19).

Entre 1930 y 1990 avizoramos una época de estudios cuantitativos y cualitativos del carácter minero, así como también la incursión de varias compañías en el austro para extraer metales y arcillas (Chacón 1986: 97-118). Esto explicaría por ejemplo la creación de la Escuela Superior de Cuenca en 1930. Poco antes de la creación de la Escuela Superior de Cuenca (1930), el Banco Central del Ecuador apoya las prácticas de laboreo de la explotación de minas en regiones como El Sigsig (provincia del Azuay) y Méndez (provincia de Morona Santiago), ambas en el austro, y esto solo después de la publicación de la obra de Teodoro Wolf (1879; 1892).

Posterior a las guerras independentistas y con la conformación de la Gran Colombia (1819), en 1822, se asegura que "el Libertador Simón Bolívar, al visitar Cuenca, después de la jornada de Pichincha, decretó que se reanudase el olvidado trabajo de las minas, comenzando por las de plata de Malal, en el actual cantón Cañar" (Crespo Toral, R. 1937 en Chacón, J. 1986: 83). Este decreto fue ratificado más adelante con el reglamento sobre minas con fecha 29 de octubre de 1829, dando en buena medida continuidad a la legislación colonial, como un rezago sobre la vida económica, en general, y minera en particular (Chacón 1986: 81-82).

Durante el siglo XVIII la economía de la ciudad de Cuenca se volvió completamente dependiente de la agricultura y ganadería, nos refiere Chacón (1986: 78), y la extracción artesanal de los metales mediante los socavones o del lavado en los ríos entró en plena decadencia. De hecho la falta de mitayos para las labores de extracción, un problema que aquejaba la minería en el austro ecuatoriano desde el siglo anterior (siglo XVII), se evidenciaba aun cuando ocasionalmente se encontraban minas prometedoras, como fue el caso de la mina en el cerro Huishil (región de Baños del Azuay), pero que no pudieron explotarse por falta de mineros y de mitayos (Chacón 1986: 79).

Durante el siglo XVII se podría caracterizar la explotación de las minas en el austro ecuatoriano como una época de sobrevivencia de las actividades de extracción que se manifestaron de manera esporádica en diferentes placeres auríferos, de plata y en menor medida de azogue. Para este período es importante resaltar la explotación intermitente de las minas del río Santa Bárbara (cantón Gualaceo, prov. Azuay), las minas del Espíritu Santo (cerca de la ciudad de Cuenca, prov. Azuay), las minas de Cañaribamba, las minas de Malal (región de Gualleturo, prov. Azuay) y las minas de Sayausí (prov. Azuay). Se trata de la conformación modesta de compañías mineras españolas de conocimientos empíricos que exploraron en los filones de las montañas. Estas empresas al realizar descubrimientos prometedores se advocaban a la tarea obligada de conseguir indios (mitayos) para las labores. El registro obligado de minas, el control de la tributación y la repartición de indios estuvo por el contrario a cargo del alcalde mayor de minas; este a su vez estuvo sujeto al corregidor de Quito. Durante este siglo encontraron su decadencia las minas de Santa Bárbara, siendo esta una de las minas que había sido más beneficiada por la Corona española para su explotación en épocas anteriores (Chacón 1986: 36). Pese a ello y como bien se explica, "algunos mineros siguieron trabajando en las minas de socavón, sin desalentarse, de forma continuada, invirtiendo dineros, haciendo compañías de explotación y adelantando obra material, con la ayuda de los indios de repartimiento" (Chacón 1986: 37). Dos factores afectaron su explotación. 1. El inicio de las rebeliones indígenas de 1579 "que comprometieron también a los indios mineros de la región. En ese año fue destruida la ciudad de Logroño y los españoles y mestizos muertos" (Chacón 1986: 36). 2. La culminación del reparto de tierras en favor tanto de los españoles como de los indios, como la señal de la 
transformación de la sociedad cuencana en agrícola y ganadera, a tal punto que "llegó a ser la tierra el bien más valioso y apreciado, hasta tornarse en el principal, por no decir el único, cuya transacción se registraba en los libros de notarías" (Chacón 1990: 123). El decaimiento general de la explotación de minas y la dependencia cada vez mayor de mano de obra indígena para las labores de la agricultura y ganadería hicieron de la minería y sus empresarios agentes competidores para el resto de la sociedad colonial cuencana.

En el siglo XVI las minas de oro de Santa Bárbara gozaban ya de buena reputación y algunos testimonios orales que dan cuenta de su riqueza fueron documentados en las crónicas tempranas de los españoles (Cieza de León 1984). La actividad minera en el corregimiento de Cuenca, fundado en 1557, fue tan llamativa para los españoles de la Colonia temprana, que el repartimiento de mano de obra indígena fue necesario reglamentar con ordenanzas emitidas en 1549 y "se dispuso que el tiempo de laboreo en las minas fuera de agosto a febrero, cuando podían ser concertados los indios una vez terminadas las lluvias y las labores agrícolas" (Chacón 1990: 135). No obstante las ordenanzas del virrey del Perú Francisco de Toledo Herrera emitidas en 1570 favorecieron la explotación de minas altoperuanas, pero no las minas de oro, plata y azogue de la jurisdicción de Cuenca, porque aquí la escasez de mano de obra indígena junto con la baja ley de los filones metalíferos "desanimaron a las autoridades fiscales a fomentar estas minas, que quedaron postergadas" (Chacón 1990: 143). Un aspecto importante de la minería en el austro ecuatoriano y de la práctica minera en el corregimiento cuencano en particular fue el descubrimiento de tesoros, porque iba en beneficio de los descubridores y del rey. Este último, según la legislación indiana, debía recibir del descubridor: 1. el quinto real y 2. la mitad de los tesoros descubiertos.

En la historia colonial del corregimiento de Cuenca raras veces se ha abordado la búsqueda y el descubrimiento de tesoros como una práctica económica que tuvo un efecto importante, aunque fragmentado, para las actividades de empresarios mineros españoles. Por el contrario, esta ha sido relegada como una actividad que solamente habría alimentado el mito y la fábula, a partir por ejemplo del rescate de oro que Rumiñahui habría desviado de su destino a Cajamarca (Chacón 1990; Salazar 1995) y que en los límites políticos del
Ecuador actual se habría encarnado al sur (Loja) en el derrotero para el descubrimiento del tesoro de Quinara y al centro-sur (Cotopaxi) para buscar el tesoro de Valverde (Salazar, 1995: 209-216). Es importante entonces que dirijamos nuestra atención a las repercusiones que tuvo el mito de El Dorado en la colonia temprana y en el corregimiento de Cuenca, en particular cuando la actividad minera entró en decadencia hacia el siglo XVII, como lo explicamos anteriormente.

\section{Actualizando el mito de El Dorado en la laguna de Ayllón del corregimiento de Cuenca (siglo XVII)}

\section{Guatavita, Paititi y "El manuscrito de Quito"}

El mito de El Dorado representa un lugar en donde el oro se encuentra en grandes cantidades e incluso las calles se encuentran tapizadas del valioso metal y fue al parecer el objetivo central para la búsqueda de riquezas de muchas generaciones de españoles y viajeros. El mito de El Dorado fue contado a Sebastián de Benalcázar en Quito en 1534 y aparece un poco más tarde en Colombia (Fernández de Oviedo y Valdés 1535), pero al parecer a partir de este momento se habría relacionado con la ceremonia del "Indio Dorado", según esto, en un festejo religioso un cacique se baña en un lago. De acuerdo con el mito un indígena moja el cuerpo del cacique con algún tipo de resina, mientras que otro sopla polvo de oro puro sobre su cuerpo con un canuto de madera:

\begin{abstract}
Dijo que cierto Rey, que sin vestido, en balsas iba por una piscina a hacer oblación según el vido, Ungido todo bien de trementina, y encima cantidad de oro molido allí para hacer ofrecimientos de joyas de oro y esmeraldas finas con otras piezas de sus ornamentos (Juan de Castellanos 1522-1607 en Magasich y De Beer 2001: 107).
\end{abstract}

Algunos autores creen que la laguna de Guatavita pudo haber sido objeto de inspiración de El Dorado, pues esta es la más célebre en la historia lacustre de estas regiones. Esta laguna era, según la tradición, el adoratorio principal de los Chibchas, "pueblo que fue una de las principales ciudades antes de la conquista y residencia de la corte del príncipe muisca" (Zerda Liborio [1882] 
1947: 16). En las inmediaciones de la ciudad de Sesquilé, al norte de la región del actual distrito de Guatavita, se encuentra a $2990 \mathrm{msm}$ en una especie de embudo rocoso la laguna de Guatavita. La tradición investigativa en esta laguna se remonta tempranamente al siglo XIX, cuando Alexander von Humboldt en 1801 realizó un dibujo de la laguna con el canal de desagüe en uno de sus costados (Humboldt 1814/25). Ya en esta época se la conocía como la laguna El Dorado. Posteriormente investigaciones científicas emprendidas por geógrafos, geólogos y arqueólogos han mantenido alimentada con nuevos conocimientos la idea demostrada de que esta laguna sirvió como algún tipo de adoratorio para la sociedad Muisca (Beisswanger 1911; Duque 1979; Espinosa, M. y Gómes L. 2000; Botero 2006). Muchos fueron los intentos tempranos por vaciar la laguna, pero al parecer el primer esfuerzo "exitoso" lo consiguió Antonio Sepúlveda en 1562. Sepúlveda construyó varios canales de desagües y campamentos alrededor de la laguna. Al parecer Sepúlveda, una vez desaguada una buena parte de la laguna, logró recuperar desde un bote y con varias inmersiones en el agua varios objetos de oro, cuyo valor ha sido incluso estimado en 12.000 pesos de aquella época (Duque 1979: 19). No obstante los hallazgos en la laguna de Guatavita, esta no fue la única laguna explorada por los españoles de la Colonia. Los mitos que asociaron ofrendas sacrificales de metales preciosos también fueron reportados para lagunas como Siecha y Fúqueme ubicadas en los macizos colombianos de la cordillera andina. Podemos concluir entonces que los complejos lacustres colombianos materializaron al extremo norte de la cordillera andina el mito de El Dorado. Por el contrario hacia el centro sur de la cadena montañosa andina una nueva versión del mito de El Dorado se habría escuchado cuando los españoles escucharon de una ciudad revestida de oro (la leyenda del Paititi), pero el escenario del mito vinculaba a las tierras bajas amazónicas.

En 1515 sobrevivientes de un naufragio de las naves de Juan Días de Solís alcanzan el Estuario de la Plata en el Atlántico y posteriormente escuchan relatos de los indios guaraníes acerca de la existencia de una ciudad de oro en la sierra de la Plata, en las selvas brasileñas. Un poco más tarde algunos de los sobrevivientes toman contacto con Sebastián de Caboto y logran convencerlo de desviar su rumbo al Asia para internarse río arriba en busca de la sierra de la Plata. Este mito curiosamente coincide espacialmente con aquel que escucharon los españoles en Cajamarca luego del asesinato de Atahualpa en 1533, pues se desarrollaría en el Antisuyo, al este de los Andes, y según este:

Allí se habrían retirado los dignatarios incas llamados orejones, con cuantos tesoros pudieron, y habrían edificado un inmenso imperio, llamado Mojos o Gran Paititi, gobernado por un joven hermano de Atahualpa y Huáscar, donde existían ciudades riquísimas en las que el oro resplandecía en todos los rincones (Payro 1927: 477 en Magasich y De Beer 2001: 108).

Las crónicas españolas tempranas del siglo XVI apuntan, según Magasich y Be Beer (2001: 109), a localizar el reino del Paititi en los llanos de Mojos, pero además lo relacionan con una isla en medio de una laguna. Este elemento geográfico ha sido analizado por Gandía para quien el Paititi habría sido un espejismo del Templo del Sol en el lago Titicaca, pues según sus interpretaciones etimológicas "la más acertada parece ser pai = monarca y titi una contracción de Titicaca, o sea, monarca del lago Titicaca" (Gandía 1929: 114 en Magasich y De Beer 2001: 109). En efecto, excavaciones arqueológicas llevadas a cabo durante varios años (2003-2006) por un equipo finlandés-boliviano muestran cómo en la isla de Pariti, en el sector boliviano del lago Titicaca, la imaginería de ofrendas sacrificiales artefactuales encontradas y datadas alrededor del 1000 AD reproduce animales y especies como serpientes, jaguares, monos y águilas arpías que solamente viven en la selva tropical. Esto sugiere que Tiwanaku mantuvo relaciones tardías con gente que vivió al pie de los Andes y muy probablemente estuvo interactuando con los habitantes de las tierras bajas propiamente dichas (Korpisaari y Pärssinen 2011: 18).

Casi un siglo posterior a las primeras documentaciones en el alto peruano referentes a la leyenda de El Dorado, el célebre sacerdote Fernando de Montesinos escuchó nuevamente rumores acerca de esta leyenda y durante sus primeros años de estancia en Lima, alrededor de 1640, trata de dar un soporte bíblico al mito de El Dorado y es en esta época en la que este mito cobra nueva fuerza en la ambición española, porque además se entremezcla con el afán de encontrar nuevas fuentes para explotar minerales preciosos: 
En sus reflexiones alrededor del Salmo 44, Montesinos explica que la riqueza del Amazonas (Ofir) fue puesta por Dios en América del Sur para atraer a los españoles, que debían evangelizar a los pueblos nativos americanos. Tanto los Libros I y III de las Memorias historiales revelan que Montesinos se basa en los ecritos del Antiguo Testamento que hablan de la Tierra de Ofir cuando habla de la riqueza de El Dorado (Resaltado mío. Hyland, S. 2008: 21-22).

Montesinos conoció una carta escrita por el padre Gerónimo Ximénez, misionero de la selva, en la que se describe "elefantes y animales nunca antes vistos en el bosque tropical" (Hyland, S. 2008: 22), pero al parecer fue un soldado acompañante de Ximénez, Francisco de Villanueva, quien aclaró a Montesinos "que unos indios habían llevado uñas de Antas y otras mayores y preguntados por los animales que tenían aquellos pies, respondieron que eran muy grandes y que en la boca tenían cuernos" (MS Nueva York, Libro I, cap. 27, f. 81.r en Hyland, S. 2008: 22). No obstante la simpatía que Montesinos tuvo por las campañas inquisitoriales del siglo XVII (Hyland, S. 2008: 29-30), el mismo terminó envuelto en la fantasía que se tejía alrededor de El Dorado y participó en al menos una expedición a la zona del Tarma en las tierras del interior para encontrar la ciudad resplandeciente de oro.

Una nueva misión se habría asignado entonces implícitamente a los españoles que pretendían buscar metales preciosos en el nuevo mundo para extirpar las creencias de los indios durante las campañas de búsqueda de El Dorado. Es precisamente esta misión la que encontramos reproducida en el corregimiento de Cuenca hacia mediados del siglo XVII y de manera concreta en las minas del río Santa Bárbara ubicadas en las cabeceras del río epónimo del actual cantón Sigsig, provincia del Azuay. Allí un grupo de mineros españoles buscó una forma poco común para la época que consistía en romper los riscos de las lagunas para desaguarlas y en principio hacerse de las pepas de oro que estarían acumuladas en grandes cantidades en el sedimento de la laguna. En lo que sigue de este ensayo vamos a referirnos a la laguna de Ayllón, porque tiene una rica tradición histórica de relatos míticos que hablan de la riqueza escondida en ella.

\section{La laguna de Ayllón, entre la ciudad perdida de Logroño de los Caballeros y el mito de Guatavita}

La laguna de Ayllón se encuentra a 10 km en línea recta al suroriente de la ciudad de Sigsig, al pie de la cordillera de Ayllón, al sur de la cordillera Real u oriental, según la carta topográfica del IGM, "San Juan Bosco", escala 1: 50.000. La laguna de Ayllón, localizada entre las lagunas de Santo Domingo al noroeste y Santa Bárbara al sur, hace parte de un complejo lacustre que se extiende desde el cerro Fasayñán al noroeste, en el cantón Gualaceo, hasta el cerro Matanga, al sur, en el cantón Sigsig (Yépez 2011). Toda esta región se caracteriza por presentar unos estilos peculiares de deformaciones crustáceas y estructuras tectónicas. Este relieve muy irregular, con valles fluviales en forma de $\mathrm{V}$ muy pronunciados, se explica en parte por sendos procesos magmáticos, tectónicos e hidrotérmicos que han ocurrido en los márgenes convergentes de la cordillera Real (Chiaridia et al. 2004: 205). En toda esta región los cerros son relativamente bajos y no superan los $4.500 \mathrm{msm}$, cada cota de altura que esté en el rango de 3.500 a 4.000 msm implica la presencia de un cerro dominante. En la unión montañosa de las cotas alrededor de $3.720 \mathrm{~m}$, llamadas localmente cerro Minas y Piedras Blancas, se forma una garganta conocida como "Ventanillas". Al pie de la formación rocosa del fondo de la figura 1 se ubica la laguna de Ayllón.

El emplazamiento geográfico de la laguna de Ayllón al sur este de la cordillera Real sitúa a esta por detrás de las tierras bajas amazónicas, es decir, por detrás de una región donde se pensó se podría encontrar la ciudad perdida de Logroño de los Caballeros y que fue precisamente objeto de búsqueda de los españoles durante los siglos XVII y XVIII, luego de su destrucción en 1579. Mientras que González Suárez escribe que a fines del siglo XVIII los vecinos de Cuenca querían descubrir las ruinas de la antigua ciudad de Logroño porque "se esparcían noticias muy curiosas acerca de las ruinas de la ciudad y la riqueza acumulada en ella" (González Suárez 1970: 210), anota Pablo Martínez en 1792:

Que examinando los archivos de Cuenca se concluía que la antigua Logroño estuvo entre Santiago y Cuenca y 'tuvo su situación en la orilla del río Paute, por donde Iban embarcados socorros de Logroño a 


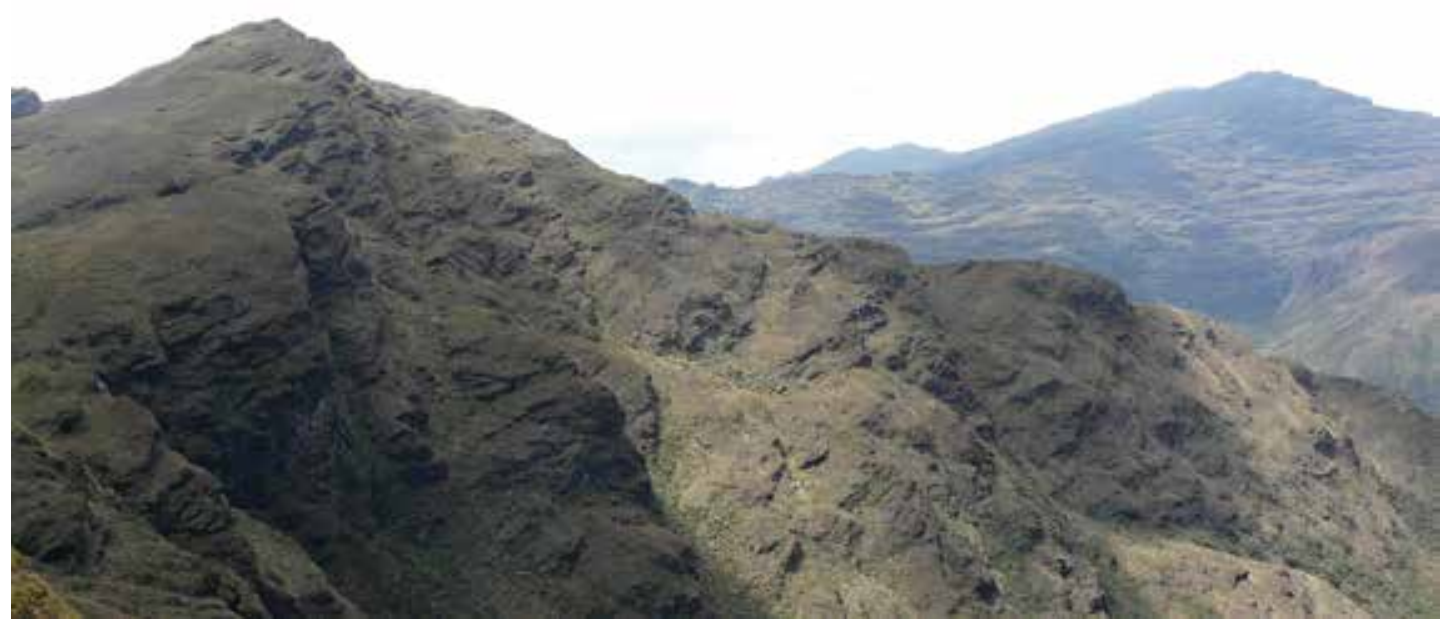

Figura 1. Paisaje natural de las formaciones lacustres el sur-este del cantón Sigsig.

Santiago', añadiendo 'El rio Paute es el riiismo que el Santiago de las Montañas, y Logroño se llamó de los Caballeros o ciudad del Oro; existió hasta 1600; tuvo Cabildo y Cajas Reales, residía en ella un Teníante del Capital General de Yaguarzongo y esta Justicia extendía su jurisdicción hasta Santiago, Sevilla del Oro, Cruces, Santa María de Nieva, Toritose (sic ¿ Tortosa?) y otras poblaciones perdidas, concluyendo que la forma de hallar la antigua Logroño era recorrer al río Santiago y 'si de esta suerte se reconoce el Santiago se ha de llegar precisamente al sitio donde estuvo Logroño y se dará con tus minas' (Maximina 1968: 127 en Lucena 1993: 219).

Podemos concluir entonces que las expediciones coloniales en el complejo lacustre de Ayllón durante el siglo XVII probablemente no buscaron en esta región la ciudad perdida de Logroño de los Caballeros, sin embargo el placer aurífero del que se explotaron las minas en Logroño en las tierras bajas podría ser el mismo que estaba en las cabeceras del río Santa Bárbara. Recordemos además que este río se llamará Paute en el valle de Tomebamba y que luego de su unión con el río Namangoza y de este con el Upano, en la selva alta, se le conoce como el río Santiago.
Una revisión de la historia oral recopilada por González Suárez a inicios del siglo XX, en las inmediaciones del cantón del Sigsig, acerca de lo que escuchó de la laguna de Ayllón, arroja elementos comunes entre la tradición oral de esta laguna y la documentación histórica de la laguna de Guatavita, ya que Ayllón también se menciona como un lugar sagrado (González Suárez 1922).

La rica tradición en expediciones (e investigaciones) respecto de sacrificios rituales materiales en la laguna de Guatavita hasta entrado el siglo XX al parecer justificaría una búsqueda intensiva de tesoros Cañaris en la laguna de Ayllón. De la misma manera se puede comprender en parte por qué en la primera mitad del siglo XX hubo unos nuevos intentos en parte exitosos de desagüe de Ayllón, aunque sin que se haya reportado la captura de los tesoros buscados.

La fotografía de la laguna de Ayllón arroja información sustancial relativa a su proceso de desagüe (Figura 2). Nótese el color blanco gris que resalta en todo el contorno de la laguna. Son varios metros de orilla descubierta por efecto del retiro de las aguas de la laguna. Este proceso favorece también la formación de islotes al interior de la laguna que separa los dos islotes grandes que se advierten en el centro a la derecha de la foto. Todo indica que esta fotografía documenta el momento en 


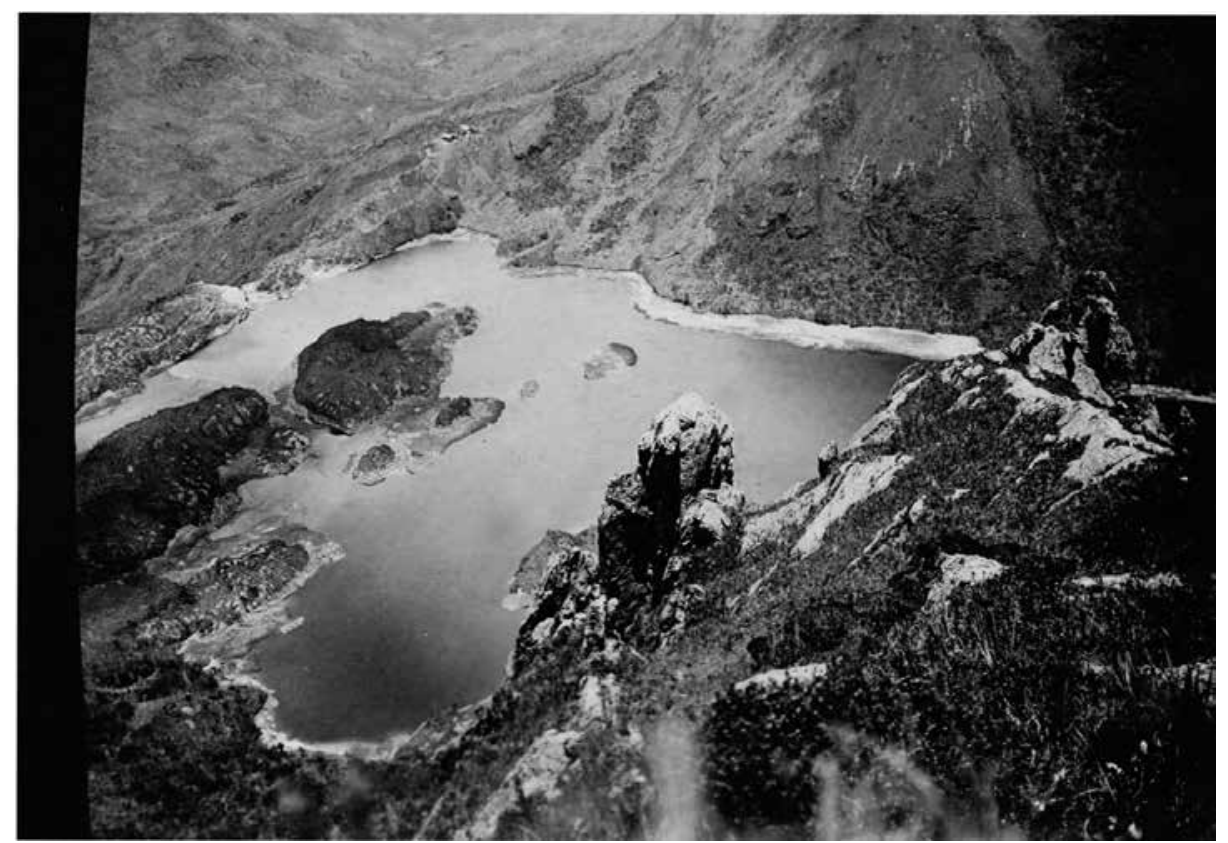

Figura 2. Proceso de desagüe de la laguna de Ayllón, 1941.

el que las aguas de la laguna empiezan a descender de nivel. Efectivamente delante de los dos islotes grandes en el risco, al norte de la laguna, se observa una superficie bastante clara con algo de contraste oscuro en el centro (Yépez 2011). Esta superficie corresponde plenamente con el área del canal de desagüe de la laguna documentado por nosotros en otra publicación (Yépez 2011: 88-89). Al anverso de la fotografía se lee la inscripción: "vista de la laguna, tomada desde una eminencia" y al reverso de la misma se complementa seguidamente: "en la que se destaca, a mano derecha, el mascarón que adoraban los incas y desde donde arrojaban presentes de oro y plata a la laguna. 1940" (Ministerio de Cultura 1941). El intento exitoso del desagüe de esta laguna no fue sin embargo propio del siglo XX. Existe información histórica anterior que refiere al desagüe de las lagunas como una manera peculiar de buscar oro durante el siglo XVII en el corregimiento de Cuenca.

\section{El complejo lacustre de Ayllón en el siglo XVII y el desagüe de las lagunas}

En un documento histórico de 1638, Francisco Fuentes de Ávila, un empresario minero, muestra su malestar al rey Felipe IV por verse obligado a abandonar sus trabajos de explotación de minas en el río Santa Bárbara para presentarse ante el corregidor de Cuenca, Juan María de Guevara y Cantos, y atender un llamado del oidor Alonso del Castillo, quien esperaba a Fuentes de Ávila en San Francisco de Quito (Yépez 2011). El oidor Alonso del Castillo quería informarse "si las lagunas Desanta Barbara prometian riqueça" (Fuentes de Ávila 1638: fol. 1), pues además había la queja de que Fuentes de Ávila evadía el tributo del quinto real y no declaraba los tesoros que encontraba en las minas de Santa Bárbara. Ciertamente que en todo el documento no existe una sola mención de una laguna en especial, sino de las lagunas del (río) Santa Bárbara.

De la lectura del documento de 1638 queda sin embargo claro que, en el proceso de apertura del canal de una de las lagunas, la falta de gente y eventualmente la falta de lluvias dificultaba la terminación de los trabajos:

Parte de la mia que se me tiene hecha para poder disponer en nada para hacer contra de Vuestra Majestad una cosa tan mal hecha, sino atender a las neçessidades grandes de Vuestra Majestad. Y el aprieto que al pressente se hallan y tan çercado de enemigos y lo poco que abenturaba y lo mucho que Dios puede dar en aquellas lagunas. Pero 
es çierto esta parte bendra asser de Vuestra Majestad porque de derecho no le tiene para apoderarla llebarse en el estado en que oy dia de la fforma tengo la labor de las lagunas. Y es que llego el corte de siete barras de hondo antes mas que menos mas que el primero a la compuerta que estaba puesta para atajar el agua que subia para que la gente pudiera trabajar y sequito y sea rompido el bordo de la laguna. Tres barras y media mas bajo de lo que estaba cortado del primero y no se a podido ber lo que hace, por no aber abido gente a que ayuden a que salgan las arenas por el corte. Y a suçedido lo que desde que se trabaja en estas minas no sea bisto que no a llobido para que ayude el agua. Y quedandose para romper tres barras y media que estas no se rompen hasta aber echado los arenales. Las tres barras y medias que estan cortadas quessera enpassando la ssemana ssanta y pasara mi entrada (Fuentes de Avila 1638: Folio 4).

De la descripción que se hace del corte del canal hay algunos elementos que podrían coincidir con el extremo sur del corte del canal de la laguna de Ayllón. Por tanto se puede considerar la hipótesis sugestiva de que las descripciones que hace el documento de 1638 acerca de los trabajos en una de las lagunas se refieran a la laguna de Ayllón que nosotros investigamos hace poco tiempo (Yépez 2011). Las "siete barras de hondo" del canal coincidirían casi perfectamente con los casi siete metros de profundidad que se registró en el perfil del canal, en los dos tramos del mismo. Esta afirmación debe tenerse como válida si es que una "barra" de largo equivaldría a un metro de largo, o dicho de otro modo, si es que las barras con las que se abrió el canal tenían un metro de largo (Yépez 2011).

La búsqueda de oro en las lagunas en este siglo obedece al parecer a la suposición de que el oro se debió haber acumulado en el fondo de la laguna por arrastre de material con las aguas que bajaban de las peñas, y no que en el fondo de las aguas reposaban tesoros de los aborígenes arrojados al lago como ofrendas, es decir, oro de "guacas". En el documento de 1638 Fuentes de Ávila se queja ante el rey indicándole de las injusticias que Luis Narbaez ( $i$ alcalde de Cuenca?) le quiere imponer (Yépez 2011). Allí distingue Fuentes de Ávila el "oro de peña" del "oro de guaca" y enfatiza que el oro de peña es el que se encontraba en las lagunas y el que él buscaba:

por ordenanças reales tiene Vuestra Majestad de las guacas de terçio que son los tessoros que llamamos en España y en este Reyno se llaman entierros y (Luis Narbaez) ya querido sustentar quelas lagunas de Sancta Barbara nosson minas sino guacas y no ffalta quien le ayuda a sustentar esta ffalsa opinión sin mirar que ay ordenanças de minas de oro corrido y de rios que es lo que estas aguas tienen y ay ordenança del señor emperador de gloriosa memoria bissaguelo de Vuestra Majestad que el minero de mina de rio, que no tomare la peña que se tenga por ynutill por ser ynfformado que en el ffirmamento de la peña se tiene de hallar la fuerça del oro y aun se practica entre mineros que esta ordenança se dio por la munchas riqueças del rio Desancta Barbara (Fuentes de Ávila 1638: Folio 4).

Resulta por demás difícil no suponer que Fuentes de Ávila no hubiese tenido una ligera esperanza en encontrar "oro de guaca" en el fondo de las lagunas que perseguía desaguar, toda vez que para la época el mito de El Dorado materializado en las lagunas de los macizos colombianos, como por ejemplo la laguna de Guatavita, o supuesto en la leyenda del Paititi, eran conocidos entre los españoles mineros quienes tenían poco conocimiento técnico en la extracción de los metales, pero mucha avidez por encontrar oro en grandes cantidades, en especial en una época en la que la explotación de minas ya no era rentable, como se explicó al inicio de este ensayo. El documento de Fuentes de Ávila arroja elementos singulares que dejan entrever el carácter religioso que del complejo lacustre y de los cerros de la cadena montañosa en esta región de la cordillera Real, aspectos que reflejan la ideología profunda de los indígenas mitayos y que era seguramente compartida por la generalidad de aborígenes, como herencia de un pasado religioso prehispánico.

\section{Sobre los "abusos" de los indios}

Fuentes de Ávila (1638) se queja de la dificultad que encontraba en reclutar gente para trabajar en el desagüe de las lagunas del río Santa Bárbara (i.e. la laguna de Ayllón): 
porque los caçiques yyndios que es gente nobelera yffaçíl, creyendo lo que se deçia y que sienpre an tenido, las lagunas de San Barbara por abuso, porque diçen sino lluebe y sepierden las comidas de sus sementeras, por seca diçen que no lluebe por que se desaguan las lagunas, y si lluebe munçho que la munçha agua les haçe daño, diçen lo mismo, que por por desaguar las lagunas lluebe ysiay mortandad en algun pueblo, diçen que aquello es causado, de desaguar las lagunas de Sancta Barbara ([Resaltado mío] Fuentes de Ávila 1638: Folio 2).

El sentido de "abuso" tal como lo refiere Fuentes de Ávila expresa contradicción en las creencias supersticiosas de los indios. La resistencia que los indios muestran para desaguar las lagunas del río Santa Bárbara iba contra los intereses extractivos de Fuentes de Ávila (Yépez, 2011). Más adelante y tal como lo preconizaba Montesinos (Hyland, S. 2008), Fuentes de Ávila indica que:

Y aunque no ffuera más que por quitarles el abuso, y el quese a tenido siempre, de tener por oraculos estas lagunas los yndios se hace servicio a Dios, de rompellas, y quitallos deste abuso" (AGI. 32. N41. Fuentes de Avila 1638: Folio 2).

Este elemento es importante porque, como anotamos anteriormente, concuerda con la labor evangelizadora preconizada por Fernando de Montesinos, para quien los empresarios mineros debían extirpar las idolatrías de los indígenas mitayos (Hydeland, S. 2008). Fuentes de Ávila añade además que:

de quessí las lagunas Desancta Barbara sedesaguan que se an de acabar los yndios, y que se an de morir todos, yassí es tanto su barbarismo, que nobayndio atrabajar alas lagunas quequando sale nolleba una piedra a su pueblo, de las que sacan en el corte, y esto para tenerla en su casa, que dicen que con aquella aunque se desaguen las lagunas Desancta Barbara y se mueran todos que él, no sea de morir por tener aquella piedra en su casa" ([Resaltado mío] Fuentes de Ávila 1638: Folio 2).

Estas aseveraciones nos acercan al sistema de creencias prehispánico, quizás incluso preincaico, que aparentemente fue compartido por los Cañaris en el austro sur del Ecuador (Yépez 2011). Según este sistema los cerros y lagunas aparecen como el lugar de morada de los Apus, Yayas o Taitas, quienes encarnan los antepasados míticos de los aborígenes. No por otra razón puede entenderse la aseveración de:

... que los alborotos arriba refferidos no se holgaban ellos poco entendiendo que no abia de pasar esa labor adelante, que el acudir loy yndios, al trabaxo, de las lagunas fforcados ydemalagana no es otra cosa mas quesolo, aquel temor queellos tienen de sus antepassados (Fuentes de Ávila 1638: Folio 2).

Ciertamente que el valle fluvial del río Santa Bárbara en sus cabeceras está acompañado de un paisaje sobrecogedor y muy probablemente representaba para los aborígenes Cañaris efectivamente el lugar de morada de los Apus o espíritus de los cerros a quienes era necesario ofrendar sacrificios para obtener beneficios o calmar su ira. Este fenómeno religioso debió estar integrado en un sistema de creencias regional. En el valle de Cuenca que incluye en el flanco oriental la cadena montañosa de Ayllón se conoce la existencia de una "geografía sagrada" que fue absorbido por el diseño de la red vial de Tomebamba incaico y "que permitía mantener contactos económicos y culturales con otras regiones e incorporaba caminos y rutas entre diversas localidades, además de cohesionar las comunidades, ayllus y señoríos étnicos entre sí y con el Estado" (Moreno Yánez 2007a: 183).

Moreno Yánez reporta para el siglo XVIII documentación escrita en la que se evidencian prácticas de ofrendas sacrificiales humanas en el cerro Guagualzhuma, al noroeste de la cadena montañosa de Ayllón. Este cerro queda al norte del valle de Cuenca, "al nororiente del pueblo de Paccha y cerca de las poblaciones de Nulti y Jadán, con la altura absoluta de 3.090 metros" (Moreno Yánez 2007a: 181).

\section{Conclusiones: en busca de una unidad ontológica}

Recientemente se ha discutido la necesidad de "reflexionar a través de las cosas", arguyendo que la distinción a priori entre las categorías "materia" 
y "significado", "personas" y "cosas", "representación" y "realidad" es cuestionable desde el punto de vista etnológico (Henare et al. 2007: 1). De manera radical e innovativa estos autores sugieren que los objetos deben tener un tratamiento semántico sui generis (Henare et al. 2007: 3), apelando por la indivisibilidad de las cosas y sus identidades significantes. Según estos autores, las cosas significan y no simplemente son portadoras de significado. La premisa de esta postura teórica se remonta a la noción de la "perspectiva multinaturalista", según esta, para los aborígenes americanos, lo humano constituye la esencia de todos los fenómenos y no lo animal (Viveiros de Castro 2004: 464, en Bray 2009: 358). Consecuentemente se presume una unidad espiritual y una diversidad corporal en el mundo natural. Cada unidad espiritual está constituida por sujetos (sean estos objetos o seres humanos) y cada sujeto tiene un punto de vista sobre el mundo externo; existe por tanto el reconocimiento explícito de una postura necesariamente desde el punto de vista del sujeto. Según esta propuesta teórica, que ha sido considerada por algunos autores como parte del nuevo paradigma en las ciencias religiosas amerindias (Bray 2009: 357-358), es el punto de vista aquel que activa al sujeto o a la creación del mismo (Viveiro de Castro 2004: 467 en Bray 2009: 358).

La esencia epistemológica de la antropología se funda en la comprensión del otro, desde el punto de vista de este. En este sentido vale recordar que las categorías emic y etic nacieron como categorías análogas a aquellas empleadas por el análisis fonológico para la investigación cultural del conocimiento (ethnoscience) y se basan en los trabajos lingüísticos de Pike (1954). Como rasgos y conceptos emic se entienden "aquellos que en las culturas investigadas operan de manera distintiva o solo para estas tiene un significado específico", en tanto que los conceptos etic "son aquellos rasgos y categorías con significado cultural de alcance universal" ([Traducido por el autor] Kokot 1999: 92). El uso de conceptos emic con una perspectiva "multinaturalista" sería en último término la recomendación primordial que hace Viveiros de Castro (2004 en Bray 2009) cuando enfrentamos el mundo espiritual-religioso andino.

Resulta un ejercicio difícil identificar las categorías emic a partir del legado escrito dejado por los españoles, para comprender, en la medida de lo posible, el sistema religioso que se tejió en torno al complejo de lagunas del río Santa Bárbara y en especial de la laguna de Ayllón. No obstante existen algunos elementos en estos relatos que nos permiten dar un salto cualitativo para describir la fenomenología religiosa del mundo andino (etic) a las categorías específicas (emic) de Ayllón y sus alrededores.

El hecho arriba relatado por Fuentes de Ávila, de que los indios que trabajaban en los cortes de las rocas y que llevaban consigo piedras para tenerlas en sus casas como protectoras de calamidades, nos lleva a pensar, desde la perspectiva etic, en dos conceptos básicos de la antropología religiosa andina. Por un lado está el término animatismo, formulado tempranamente en el siglo XIX, y por otro lado está el de animismo como respuesta al anterior y creado en el mismo siglo por representantes del evolucionismo clásico. Según el primer concepto los objetos se caracterizan por poseer una fuerza inmanente (Marett, 1909), las piedras de los cortes que reposaban en las casas de los indios emanarían una especie de fuerza protectora, muy parecida a las funciones que aparentemente tenían los amuletos en el mundo andino:

Los amuletos americanos están dotados de individualidad, entendemos afirmar que su poder es particular y propio de cada uno de ellos y que es él que los señala, da a conocer e identifica, entendiendo así, oponer esta noción a la de colectividad, y afirmar que su poder es inherente en cada uno de ellos, no común de todo un género, tipo o categoría; o más claramente, aunque con menos precisión, que están dotados de vida propia y no son fórmulas o símbolos, que se pueden repetir al infinito (Jijón y Caamaño 1990: 110-111).

Desde la perspectiva emic la categoría seminal para entender la religión del mundo andino y que tiene estrecha relación con el fenómeno descrito por Fuentes de Ávila es camaquen. De acuerdo con la lectura del estudio introductorio del Manuscrito de Huarochiri (Sálomon y Urioste 1991, en Bray 2009: 358), camay es fundamentalmente entendido como un tipo de esencia específico, fuerza o poder más que algo generalizado. Camay tiene también la connotación de llevar algo en existencia mediante la transfusión de energía de la materia existente, una idea opuesta a la creación de algo de la nada (Bray, 2009: 358). Los trozos de piedra que llevaban los indios a sus casas transmitían la 
misma energía protectora de los cerros y lagunas, sus huacas sagradas, en el ambiente doméstico que vivían los aborígenes. La manifestación de este concepto expresada en las piedras trasladadas se deja comparar con el concepto de conopas, usado en el mundo andino ecuatorial:

Lo característico de esta forma de religión (los conopas) es que el espíritu, que habita en el objeto, puede entrar o salir de él, a su voluntad, y obligársele a volver a su morada, practicando ceremonias adecuadas; y que al fetiche se le puede abandonar cuando ya no se lo juzga necesario, no cabe duda que los conopas y objetos semejantes de América no son fetiches aunque tengan tantos puntos de contacto con éstos" (Jijón y Caamaño 1990: 113).

Para alcanzar una perspectiva emic y describir un hecho social total a partir de los relatos de Fuentes de Ávila, es necesario considerar la posiblidad de que fuerza (camaque) y alma (huaca) estuvieron presentes en las piedras trasladadas de su lugar originario (los riscos de las lagunas) y que luego fueron guardadas en las casas de los indios para que les den su protección y evitar así el castigo de los cerros y lagunas (sus huacas), porque "de quessí las lagunas Desancta Barbara sedesaguan que se an de acabar los yndios" (Fuentes de Ávila 1638). En el Manuscrito de Huarochiri, anota Salomon también, que las huacas no solamente son objetos con características animistas, sino por el contrario que ellas tienen "personalidades individuales vibrantes" (Salomon 1991: 19 en Bray 2009: 359) y que son "personas de facto":

El mundo de los Checa no parece haber estado hecho de dos tipos de materia -(i.e.) materia y espíritu-como para los Cristianos; (al contrario) las huacas fueron hechas de materia energizada, como todo lo demás, y ellas actuaron en la naturaleza, no sobre y fuera de ella como lo hacen las creencias sobrenaturales occidentales" ([Traducido por el autor] Salomon 1991: 19 en Bray 2009: 359).

Además de las cualidades aglutinantes como fuerza y alma es necesario tener en cuenta el elemento de adscripción con los antepasados que los aborígenes Cañaris tuvieron con el complejo de cerro y lagunas, pero en especial con la laguna de Ayllón. En el documento dejado por Ávila se menciona a las lagunas como morada de los antepasados, según las "supersticiones" de los indios. En los mitos de origen de los Cañaris se indica en repetidas ocasiones a las lagunas como el lugar específico en el que vive la serpiente fundadora del pueblo Cañari (shin-shin), una especie de tótem fundador, es decir, de "una relación ritualizada entre grupos humanos y elementos de la naturaleza (animales, plantas, fuerzas naturales) a las que se asigna condición de antepasados" (Aguirre 1982: 250 en Moreno Yánez 2007b: 106) o "de parientes rituales que, en la práctica, cumplen la función de clasificación social identitaria y de diferenciación de otros clanes o grupos étnicos" (Moreno Yánez 2007b: 106).

Es factible suponer sin lugar a dudas que el complejo de lagunas del río Santa Bárbara fue una morada importante del panteón Cañari, pero por el momento nos es difícil reconocer una jerarquía de dioses con funciones definidas y designados por nombres propios al este del pueblo de Sigsig, debido a la falta de fuentes documentales tempranas. Precisamente la historia socioeconómica del austro ecuatoriano debe ser complementada con la lectura e interpretación de una ideología profunda que subyace en las crónicas tempranas y tardías de los registros notariales de las empresas mineras españoles. El reto está planteado, hace falta escribirla.

\section{Agradecimientos}

La Pontificia Universidad Católica merece un especial reconocimiento por su apoyo académico y económico en la preparación de este manuscrito, igual que el Instituto Nacional de Patrimonio Cultural, Regional 6, por haber financiado en el año 2010 una investigación subacuática en la laguna de Ayllón. Agradezco además al Dr. Napoleón Almeida, organizador del simposio "Principios culturales y tecnológicos asociados a las modalidades de ocupación territorial: Desde el periodo prehispánico hasta la implantación colonial" sostenido en la Universidad de Tarapacá (noviembre 2014), donde se presentó una versión preliminar de este trabajo. A las Dras. Christiana Borchiart de Moreno y Viviana Velasco y a Mtr. Cristóbal Landázuri por su interés en las conversaciones relacionadas con la versión final del manuscrito. 


\section{Referencias Citadas}

Beisswanger, $\mathrm{K}$.

1911 Im Lande der heiligen Seen - Reisebilder aus der Heimat der Chibcha-Indianer (Kolumbien). Nürnberg: Durck und Verlag von Beisswanger.

Botero, J.F.

2006 Informe de la prospección y monitoreo arqueológico en la Reserva Laguna de Guatavita. Bogotá: ICAHN.

Bray, $T$.

2009 An archaeological perspective on the Andean Concept of Camaquen: thinking trhough late pre-Columbian ofrendas and huacas. Cambridge archaeological journal 19, 3. pp. 357-366.

Castellanos, Juan

1942 Historia de la Gobernación de Antioquia y de la del Chocó. Bogotá: Editorial A, B, C.

Chacón, G.

1986 Historia de la minería en Cuenca. Cuenca: Universidad de Cuenca.

Chacón, G.

1990 Historia del corregimiento de Cuenca (1557-1777). Colección Histórica XIX. Quito: Banco Central del Ecuador.

Chiaridia, M., Fontboté, L., Beate, B.

2004 Cenozoic continental arc magmatism and associated mineralization in Ecuador, Mineralium Deposita 39: 204-222.

Cieza de León, $\mathrm{P}$.

1984 La crónica del Perú. Madrid: Historia 16.

Domínguez, E.

1999 Cultura Cañare. Azogues (Ecuador): Ilustre municipio de Azogues.

Fernández de Oviedo y Valdés, Fernando

1535 Historia General de las Indias. Sevilla (http: //books. google.com.ar/books?id=T_1OAAAAcAAJ\&printsec=fro ntcover\&hl $=$ es\&source $=g b s \_g e \_s u m m a r y \_r \& c a d=0 \# v=0$ nepage \&q\&f=false)

Duque, L.

1979 Las primeras exploraciones en la laguna de Guatavita, in: Boletín Museo del Oro, Año 2, Bogotá: Banco de la República.

Espinosa, M. y Gómes, L.

2000 Guatavita - Un encantamiento de Agua, Oro, Tierra y Vientos. Bogotá: ediciones Cultura Hispánica.

Fuentes de Ávila, F.

1636 Sobre desagüe de la laguna de Santa Bárbara (título atribuido). AGI/Q. Cedularios209,L.2,F.103R-103V. (http: //pares.mcu.es/ParesBusquedas/servlets/Control_servlet)

Fuentes de Ávila, F.

1638 Sobre lo tocante al desagüe de las lagunas de Santa Bárbara que le está cometido. AGI/ Q Cartas y expedientes de personas seculares 32, N. 41. (http: //pares.mcu.es/ ParesBusquedas/servlets/ImageServlet).

González Suárez, F.

1922 Estudio histórico sobre los Cañaris, antiguos habitantes de la provincia del Azuay en la República del Ecuador. Cuenca: Universidad de Cuenca.

González Suárez, F.

1970 Historia General de la República del Ecuador. T. III. Quito, Casa de la Cultura Ecuatoriana.

Henare, A., Martin H. y Sari W. (eds.).

2007 Thinking through things. London: Routledge

Hyland, S.

2008 El manuscrito de Quito. Una historia preservada por Fernando de Montesinos. Quito: IÁCOBOS.
Humboldt, A.v. (1814/25). Voyage aux régions equinocciales du Nouveau Continent, fait en 1799, 1800, 1801, 1802, 1803, 1804. T. 1-3. París (Voyage de Humboldt et Bonpland. Partie 1. Relation Historique).

Instituto Geográfico Militar (s.f.). Carta topográfica San Juan Bosco, escala 1: 50000. Quito.

Jijón y Caamaño, J.

1990 La religión del imperio de los Incas, Los fundamentos del culto. Huacas, Conopas, Apachitas, Urcos, Huancas, Machais. vol. I. Quito: Casa de la cultura ecuatoriana "Benjamín Carrión".

Korpisaari, A. y Pärssinen M.

2011 Pariti. The ceremonial Tiwanaku pottery of the island in the Lake Titicaca. Sastamala: Vammalan Kirjapaino oy.

Kokot, W.

1999 Emisch/Etisch. Wörtebuch der Völkerkunde. Berlin: Dietrich Reimer Verlag.

Lucena, Manuel

1993 La ciudad perdida de Logroño y la última fundación misional en el Reino de Quito (1818): oro, jíbaros y misioneros. Estudios de historia social y económica de América, $N^{o} 10,1993$, págs. 217-232.

Marett, R.

1909 The treshold of religion. London: Methuen \& Co. Ltd. (https: //archive.org/details/thresholdofrelig00mareuoft)

Magasich, J. y J-M de Beer

2001 América mágica. Mitos y creencias en tiempos del descubrimiento del nuevo mundo. Santiago de Chile: LOM (https: //books.google.com.ec/books?id=fhjg9NOw3lgC\&pg)

Moreno Yánez, S.

2007a Ofrenda sacrificial en el Guagualzuma. En: Fernando S. Garcia (ed.), II. Congreso Ecuatoriano de antropología y Arqueología, tomo 2: 175-202' Quito: Abya Yala.

Moreno Yánez, S.

2007b Historia antigua del País Imabaya. Quito: Studio21.

Ministerio de Cultura.

1940 Ficha 4563 de la laguna de Ayllón. Cuenca: Banco Central del Ecuador.

Pike, K.

1954 Language in relation to a unified theory of the structure of human behavior. part 1. Glendale, Calif.: Summer Institute of Linguistics.

Sacher, W. y A. Acosta

2012 La minería a gran escala en Ecuador. Análisis y datos estadísticos sobre la minería industrial en el Ecuador. Quito: Abya-Yala.

Salazar, E.

1995 Entre mitos y fábulas: el Ecuador aborigen. Quito: Corporación Editora Nacional.

Wolf. T.

1879 Relación de un viaje geognóstico de la provincia del Azuay. Guayaquil: Imprenta del Comercio.

Wolf, T.

1892 Geografía y geología del Ecuador. Leipzig: Brockhaus

Yépez, A.

2001 Investigaciones subacuáticas en las lagunas de Busa y Ayllón, provincia del Azuay (etnografía, etnohistoria y arqueología). Serie de Estudios: investigaciones arqueológicas en Azuay y Morona Santiago. Quito: INPC.

Zerda, L.

[1882] 1947 El Dorado. Biblioteca popular de cultura colombiana. Bogotá: "Cahur". 